\title{
Elevated serum CEA levels are associated with the explosive progression of lung adenocarcinoma harboring EGFR mutations
}

\author{
Yuan Gao ${ }^{1}$, PingPing Song ${ }^{2,4^{*}}$, Hui Li ${ }^{2}$, Hui Jia ${ }^{3}$ and Bailiang Zhang ${ }^{2}$
}

\begin{abstract}
Background: Serum carcinoembryonic antigen (CEA) levels are a predictor of epidermal growth factor receptor tyrosine kinase inhibitor (EGFR-TKI) efficacy and are associated with epidermal growth factor receptor (EGFR) gene mutations. However, the clinical significance of plasma CEA level changes during different cycles of target therapy is unknown for lung adenocarcinoma patients with sensitizing EGFR mutations.
\end{abstract}

Methods: In total, 155 patients with lung adenocarcinoma were enrolled in this retrospective study between 2011 and 2015. EGFR mutations were detected by RT-PCR (real-time quantitative PCR). Plasma CEA levels were measured prior to different EGFR-TKI treatment cycles. Computed tomography (CT) scans were conducted every 2 months to assess the therapeutic efficacy.

Results: Serum CEA concentrations were significantly associated with EGFR mutations $(p<0.05)$. Furthermore, in all patients treated with EGFR-TKIs, the serum CEA levels increased with disease progression $(p<0.005)$. A COX multivariate analysis revealed that CEA levels 16.2 times above normal were associated with early disease progression (HR, 5.77; 95\% Cl:2.36 14.11; $p<0.001)$. Based on this finding, a threshold was set at the median time of 8.3 months. Patients with EGFR mutations exhibited a median progression-free survival time of 12.8 months. Serum CEA levels were markedly increased compared to levels measured 4.5 months prior to the changes detected via CT scans for patients resistant to EGFR-TKIs.

Conclusions: Elevated CEA levels during targeted therapy may be a more sensitive predictor of explosive lung adenocarcinoma progression in patients harboring mutant EGFRs compared to traditional imaging methods.

Keywords: Biomarker, EGFR, EGFR-TKIs, Mutation, Response

\section{Background}

Lung cancer is the leading cause of cancer-related mortality worldwide, and non-small cell lung cancer (NSCLC) is the most common form of lung cancer. Many NSCLC patients present with an advanced disease stage upon initial diagnosis [1]. Patients with tumors that harbor activating mutations in the epidermal growth factor receptor (EGFR) benefit greatly from treatment with EGFR tyrosine kinase inhibitors (TKIs) compared with patients whose tumors lack these

\footnotetext{
* Correspondence: spp128@126.com

2Department of Thoracic Surgery, Shandong Tumor Hospital and Institute, Jinan, Shandong Province 250117, China

${ }^{4}$ Department of Thoracic Surgery, Shandong Cancer Hospital and Institute, Jiyan Rd. 440, Jinan, Shandong 250117, People's Republic of China

Full list of author information is available at the end of the article
}

mutations [2-7]. One such EGFR-TKI is the orally administered, targeted agent erlotinib, which inhibits the tyrosine kinase domain of the EGFR. Erlotinib is approved for second-line use based on the positive results of a phase 3 BR.21 trial [8] in which erlotinib improved overall survival (OS) compared with the best supportive care. Erlotinib also has clinical benefits as a first-line therapy for advanced NSCLC. The tumor response rate was $10-20 \%$, and the median survival duration was 10.9 12.9 months in phase 2 studies $[9,10]$. However, almost all patients suffered from tumor progression and inevitably became resistant to EGFR-TKIs within 8-12 months (a phenomenon referred to as acquired resistance).

Currently, the standard method of measuring the efficacy of a lung cancer treatment is anatomical imaging, 
including computed tomography (CT) scanning, which measures the size of malignant lesions before and after treatment. However, the use of anatomical imaging methods to assess treatment efficacy presents a number of drawbacks, the most critical of which is a delay in treatment due to changes in tumor size. Furthermore, the efficacy of targeted drugs is often not reflected by a change in tumor size but rather by changes in cell metabolism. Therefore, the identification of clinical biomarkers in patients with EGFR mutations may prove useful when anatomical analyses are not feasible.

Several serum markers are considered to be prognostic and predictive markers of NSCLC. Among these markers, carcinoembryonic antigen (CEA) is a sensitive and useful tumor marker for cancer diagnosis and prognosis and the assessment of therapy [6-8]. According to recent reports, CEA is a significant predictor of sensitivity and survival in patients treated with gefitinib [9-11]. The present study (1) compared the significance of CEA levels with other clinical characteristics (i.e., age, sex, smoking history, performance status [PS], and CYFRA1-1) and (2) determined whether the serum CEA levels correlated with EGFR-TKI resistance. This correlation would permit the use of CEA as a biomarker in NSCLC patients and would aid in identifying treatment candidates with reversible and irreversible EGFR-TKI resistance and candidates for whom an early intervention with combined chemotherapy and radiotherapy is more appropriate.

\section{Methods}

\section{Patients}

In total, 155 primary lung adenocarcinoma patients, who had been hospitalized at the Department of Respiratory, Oncology and Thoracic Surgery in Shandong Provincial Tumor Hospital between August 8, 2011, and March 8, 2015 , were enrolled in this retrospective study. The enrolled patients tested positive for an EGFR mutation and had received EGFR-TKI as a 1st, 2nd, or 3rd line of treatment $[6,12]$. Patients with locally advanced (stage IIIB), metastasized (stage IV), or post-surgically relapsed NSCLC were confirmed for EGFR mutations and received either gefitinib $250 \mathrm{mg} / \mathrm{d}$ or erlotinib $150 \mathrm{mg} / \mathrm{d}$ orally. The clinical stage was determined by the tumor, node, and metastasis (TNM) classification system (7th edition). The following inclusion criteria were utilized for this study: patients had pathologically identified adenocarcinoma; had received an initial therapy (including chemotherapy, surgery or chemoradiotherapy); and had survived for more than 1 month. Histological subclassification was performed according to the World Health Organization classification. A CT scan was performed to assess the tumor size within 28 days prior to initiating treatment and was repeated every 2 months. Serum tumor markers and CT scans were measured simultaneously. All responses were defined according to the Response Evaluation Criteria in Solid Tumors (RECIST) criteria. A response was confirmed at 4 weeks (for a complete or partial response) or 6 weeks (for stable disease) after the first documentation. Other inclusion criteria included an Eastern Cooperation Oncology Group (ECOG) performance status of 0-3 [13]. Patients who had received prior treatment with oral EGFR-TKIs or were allergic and/or intolerant to these drugs were excluded from the study. The progressionfree survival (PFS) and overall survival (OS) of the metabolic responders and non-responders were the end points of the study. The baseline patient characteristics are presented in Table 1. This study complied with the guidelines of the local ethics committee.

\section{Measurement of serum tumor marker levels}

Serum CEA (normal range: 0-3.4 $\mathrm{ng} / \mathrm{ml}$ ) and CYFRA 21-1 (normal range: $0-3.3 \mathrm{ng} / \mathrm{ml}$ ) were measured via an electrochemiluminescence immunoassay on an automatic analyzer (Elecsys200; Roche Diagnostics Mannheim, Basel, Switzerland) before TKI treatment.

\section{Determination of EGFR mutation}

EGFR mutation analysis was performed via a fragment analysis using polymerase chain reaction (PCR) and the Cycleave real-time quantitative PCR techniques (SRL Inc., Tokyo, Japan).

Table 1 Patient characteristics

\begin{tabular}{lll}
\hline Characteristic & No. of Patients & Percentage \\
\hline Sex & 63 & $34.2 \%$ \\
Male & 92 & $65.8 \%$ \\
$\quad$ Female & & \\
Clinical Stage & 57 & $36.8 \%$ \\
I,II & 98 & $63.2 \%$ \\
III,IV & & \\
Smoking history & 63 & $34.2 \%$ \\
Ever & 92 & $65.8 \%$ \\
Never & & \\
Age,y & 74 & $47.7 \%$ \\
$<59$ & 81 & $52.3 \%$ \\
$\geqq 59$ & & \\
ECOG PS & 152 & $98.1 \%$ \\
$0-1$ & 3 & $1.9 \%$ \\
$2-3$ & & \\
Median age of patients 59y (range,38-81y) & \\
\hline
\end{tabular}

Patient characteristics 


\section{Statistical methods}

There were no missing data in our study. We used SPSS 17.0 statistical software (SPSS Inc., Chicago, IL, USA) for data processing. The $X^{2}$ test, Fisher's exact test and multivariate logistic regression analysis were used to analyze the associations between EGFR mutations and clinical factors. Survival was estimated using the KaplanMeier method. Overall survival was measured as the date of the first course of initial therapy to the date of death or the last follow-up examination. A log-rank test was performed to evaluate significant differences in the overall survival among the groups. $P$ values $<0.05$ were considered significant. A multivariate analysis using the Cox proportional hazards model was used to establish the association between the clinical variables and survival.

\section{Results}

Patient characteristics

The clinicopathological characteristics of the 155 patients are summarized in Table 1 . Ninety-two patients $(65.8 \%)$ were women, and 92 patients $(65.8 \%)$ were nonsmokers. The patient age ranged from 38 to 81 years (median: 60 years). Fifty-seven patients were classified as pathological stage classes I and II, and 98 patients were classified as III and IV. One hundred fifty-two patients (98.1\%) had a PS of $0-1$, and three (1.9\%) patients had a PS of 2-3. The median OS and PFS were 28.5 and 12.8 months, respectively.

\section{Relationship between CEA levels and EGFR gene mutations}

A single factor $x^{2}$ test showed that EGFR mutation was associated with gender, age, smoking history, and the serological levels of CEA and CYFRA 21-1 $(p<0.05$; Table 2). The multivariate logistic analysis revealed that patient gender and serological CEA levels were correlated with EGFR mutation $(p<0.05)$ (Table 3).

A ROC curve was drawn, and the area under the curve was calculated. The area under the curve for CEA was 0.567 (95\% CI: $0.476 \sim 0.657, p<0.001$ ). When the CEA cut-off was $3.4 \mathrm{ng} / \mathrm{ml}$, the sensitivity was $69.6 \%$ and the specificity was $48.8 \%$ (Figure 1 ).

\section{Association of serum markers and the response to EGFR- TKIs}

We evaluated the efficacy of EGFR-TKIs via CT scanning and serum tumor marker concentrations (CEA) every 2 months. The patients were divided according to serum CEA levels into elevated and non-elevated groups in progress group by CT scanning. A $X^{2}$ test revealed that increased serum CEA levels were related to disease progression $(p<0.005)$. Patients were then divided into two groups according to the average value (CEA levels 16.2
Table 2 Analysis of EFGR mutation

\begin{tabular}{|c|c|c|c|c|}
\hline Clinical Characteristic & Sample(n) & EGFR mutation(n) & $x^{2}$ & $P$ \\
\hline \multicolumn{5}{|l|}{ Gender } \\
\hline Female & 92 & 47 & 3.957 & 0.047 \\
\hline Male & 63 & 22 & & \\
\hline \multicolumn{5}{|l|}{ Age } \\
\hline$<59$ & 74 & 30 & 4.230 & 0.040 \\
\hline$\geqq 59$ & 81 & 39 & & \\
\hline \multicolumn{5}{|l|}{ Stage } \\
\hline $1, \|$ & 57 & 21 & 2.150 & 0.143 \\
\hline$\| I I, I V$ & 98 & 48 & & \\
\hline \multicolumn{5}{|l|}{ PS Score } \\
\hline $0-1$ & 152 & 68 & 0.155 & 0.694 \\
\hline $2-3$ & 3 & 1 & & \\
\hline \multicolumn{5}{|l|}{ Smoker } \\
\hline Ever & 63 & 22 & 3.957 & 0.047 \\
\hline Never & 92 & 47 & & \\
\hline \multicolumn{5}{|l|}{ CEA } \\
\hline$<3.4 \mathrm{ng} / \mathrm{ml}$ & 63 & 21 & 5.374 & 0.020 \\
\hline$\geqq 3.4 \mathrm{ng} / \mathrm{ml}$ & 92 & 48 & & \\
\hline \multicolumn{5}{|l|}{ Cyfra21-1 } \\
\hline$<3.3 \mathrm{ng} / \mathrm{ml}$ & 64 & 44 & 25.920 & 0.001 \\
\hline$\geqq 3.3 \mathrm{ng} / \mathrm{ml}$ & 91 & 25 & & \\
\hline
\end{tabular}

A single factor $\mathrm{X}^{2}$ test showed that EGFR mutation was associated with gender, age, smoking history, and the serological levels of CEA and CYFRA 21-1

times higher than normal) in elevated group. According to the Cox regression analysis, CEA levels 16.2 times higher than normal at any point during the 2 months prior to the determination of progress represented an early response to disease progression (HR, 5.77; 95\% CI:2.36 14.11; $p<0.001$; Table 4$)$. We noted that the median time until this threshold (i.e., CEA levels at least 16.2 times higher than normal) was reached was 8.3 months. However, for patients with EGFR mutations, the median was 12.8 months.

\section{Discussion}

EGFR mutation predicts the efficacy of EGFR-TKIs in patients with advanced NSCLC. However, acquiring an adequate tissue sample for an EGFR mutational analysis is not often feasible, particularly in patients with advanced disease $[2,8,14]$. A recent study reported that

Table 3 Futher analysis of the association of EGFR mutation

\begin{tabular}{llll}
\hline Factor & \multicolumn{3}{l}{ EGFR Mutation } \\
& OR & P & $95 \% \mathrm{Cl}$ \\
\hline Gender & 0.479 & 0.034 & $0.243 \sim 0.946$ \\
CEA & 2.529 & 0.001 & $1.283 \sim 4.984$
\end{tabular}

The multivariate logistic analysis revealed that patient gender and serological CEA levels were correlated with EGFR mutation 


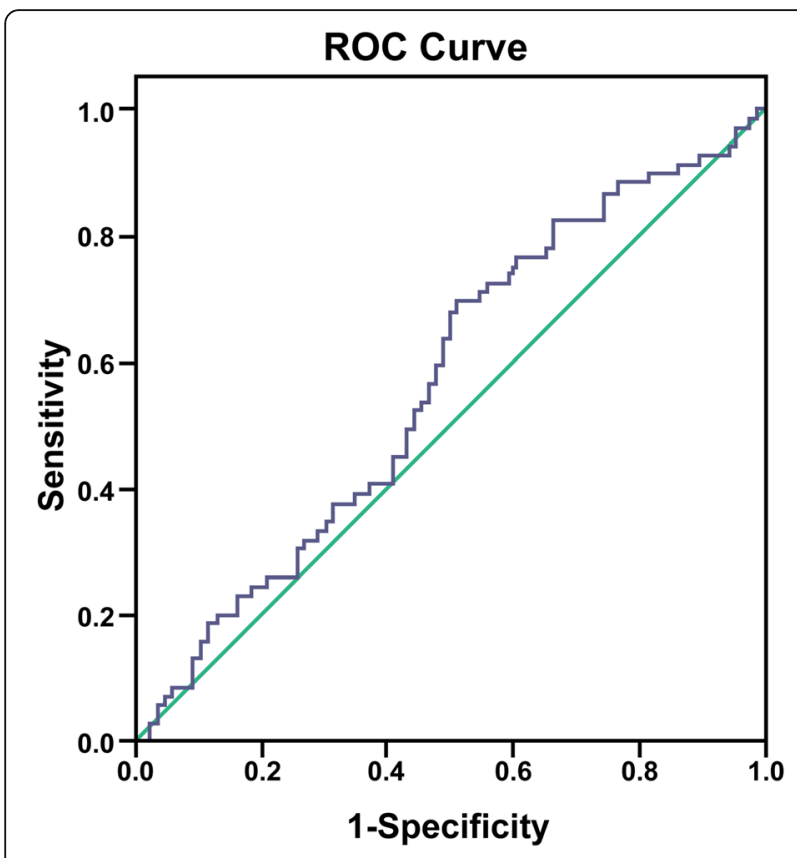

Diagonal segments are produced by ties.

Fig. 1 A ROC curve was drawn, and the area under the curve was calculated. The area under the curve for CEA was 0.567 (95\% Cl: $0.476 \sim 0.657, p<0.001)$. When the CEA cut-off was $3.4 \mathrm{ng} / \mathrm{ml}$, the sensitivity was $69.6 \%$ and the specificity was $48.8 \%$

molecular analyses of circulating tumor cells obtained from the peripheral blood of patients with lung cancer was useful for monitoring changes in epithelial tumor genotype during the course of treatment. However, this type of molecular analysis can be difficult due to the requirement of a specific, microfluidic-based device - the CTC chip. Moreover, there are approximately 486 types of EGFR-TKI domain mutations across 87 species, and new mutations are continually being identified $[15,16]$. Recently, the attention moved to the possibility of isolation and analysis of cell-free tumor DNA (cftDNA) that, to date, represents the best candidate for identification and monitoring of molecular tumor-related alterations in blood of patients with cancer [17]. Circulating DNA fragments carrying tumor specific sequence alterations cftDNA are found in the cell-free fraction of blood, representing a variable and generally small fraction of the total circulating DNA. cftDNA has a high degree of specificity to detect EGFR gene mutations in NSCLC. Fragments of circulating DNA were isolated in plasma many years ago [18]. In particular, patients with cancers present higher levels of circulating DNA comparing to healthy volunteers because of the presence of tumoral counterpart, which express the same molecular abnormalities expressed by DNA of primitive mass [19]. The elevate cellular turn over and consequent cellular necrosis and apoptosis cause a massive release of tumoral DNA into the bloodstream were it can be isolated and analyzed. Therefore, tumor size, localization and vascularity may influence cftDNA plasmatic levels. It is also possible that part of cftDNA comes from CTCs lysis [19]. The analysis of cftDNA, defined as liquid biopsy, could be repeated every time needed and without any discomfort for patients. Moreover, the mutational analysis of cftDNA demonstrated a signicantly better sensitivity if compared with CTCs one, establishing cftDNA as the best circulating source for molecular analysis [20]. Information derived from liquid biopsy could be used in future for early cancer diagnosis, assessment of genetic determinants for targeted therapies, monitoring of tumor dynamics and early evaluation of tumor response, identification of resistance mechanisms [19]. cftDNA could be a relevant biomarker to molecular diagnosis and monitor treatment resistance, because of its sensitivity and specificity, but it really needs reproducible and standardized methods, both for the extraction and for its analyses. Regarding the mutation analysis of ctDNA, a large number of technologies is now available to analyze mutations in cftDNA, including automatic sequencing, real-time polymerase chain reaction (PCR) platforms, mass spectrometry (MS) genotyping, ampli cation protocols with magnetic beads in oil emulsions [beads, emulsion, ampli cation and magnetics (BEAMing)] and nextgeneration sequencing (NGS), digital PCR platforms [21-25]. The sensitivity range of the available techniques

Table 4 Correlation between CEA levels and disease progression

\begin{tabular}{|c|c|c|c|c|c|c|c|c|c|}
\hline & & \multirow[t]{2}{*}{ B } & \multirow[t]{2}{*}{ SE } & \multirow[t]{2}{*}{ Wald } & \multirow[t]{2}{*}{$d f$} & \multirow[t]{2}{*}{ Sig. } & \multirow[t]{2}{*}{$\operatorname{Exp}(B)$} & \multicolumn{2}{|c|}{ 95.0\% Cl for $\operatorname{Exp}(B)$} \\
\hline & & & & & & & & Lower & Upper \\
\hline Step 1 & CEA & 2.007 & .434 & 21.377 & 1 & .000 & 7.443 & 3.178 & 17.428 \\
\hline \multirow[t]{2}{*}{ Step 2} & Age & .701 & .355 & 3.908 & 1 & .048 & 2.017 & 1.006 & 4.043 \\
\hline & CEA & 2.041 & .444 & 21.147 & 1 & .000 & 7.695 & 3.225 & 18.361 \\
\hline \multirow[t]{3}{*}{ Step 3} & Stage & .855 & .428 & 3.997 & 1 & .046 & 2.351 & 1.017 & 5.435 \\
\hline & Age & .814 & .361 & 5.084 & 1 & .024 & 2.257 & 1.112 & 4.580 \\
\hline & CEA & 1.752 & .456 & 14.754 & 1 & .000 & 5.769 & 2.359 & 14.108 \\
\hline
\end{tabular}

According to the Cox regression analysis, CEA levels 16.2 times higher than normal at any point during the 2 months prior to the determination of progress represented an early response to disease progression 
varies from 15 to $0.01 \%$, but one of the major gaps in this field is the lack of standardization of techniques, in order to understand how those techniques are costeffective and reliable to the clinical needs.

Therefore, simpler and more accessible predictors of EGFR mutations, such as surrogate markers, are necessary. CEA is the product of the CEACAM5 gene, which is expressed only in epithelial cells. CEA is found more abundantly on the apical surface of the gastrointestinal epithelium but is also found in other mucosal epithelia cells, such as in the lung [26]. Although CEA was often falsely elevated in smokers and in patients with restrictive or obstructive pulmonary diseases [27-29], abnormally elevated CEA levels were reported in $30-70 \%$ of patients with NSCLC. Abnormally elevated CEA levels are most frequently observed in patients with adenocarcinoma and advanced stage carcinoma [30]. In addition, high serum CEA levels are associated with a poor prognosis in patients with NSCLC, regardless of treatment [30, 31]. According to Japanese scholars, patients with elevated serum CEA levels responded better to gefitinib. Furthermore, recurrent lung adenocarcinoma patients with high serological CEA levels have a higher EGFR mutation rate after surgery and higher serological CEA levels. These findings are attributed to a possible antiapoptotic signal in the mutant EGFR pathway that could elevate the expression level of the CEA protein [32]. However, the specimens used for genetic testing were surgical specimens obtained prior to disease recurrence and may not represent all the biological characteristics of a recurrent tumor [33]. In our study, the serum CEA level in the EGFR gene mutation group was significantly higher than in the non-mutated group. Both the univariate and multivariate analyses indicated that the serum CEA levels correlated with EGFR mutations (higher serum CEA levels were associated with higher EGFR gene mutation rates). Our data are similar to the findings of Okamato et al. [34]. Shoji et al. [35] reported that the rate of EGFR gene mutation significantly increased as the serum CEA levels increased (for serum CEA levels $<5, \geq 5$ (but $<20$ ), and $\geq 20$, the rates of EGFR gene mutation were 35,55 and $87.5 \%$, respectively; $p=0.040$ ).

Several reports have described the relationship between serological markers and the curative effect of EGFR-TKIs. However, these reports did not perform EGFR mutation testing or dynamic monitoring of CEA levels to predict EGFR-TKI resistance. Therefore, these reports cannot determine the most effective treatment for early intervention. Despite the high responsiveness of tumors bearing activating EGFR mutations, almost all patients become resistant to TKIs. Multiple molecular mechanisms may underlie this resistance, including secondary EGFR mutations, bypassed signaling activation, and phenotypic transformation. Because multiple molecular mechanisms may lead to EGFR-TKI resistance, it is important to non-invasively detect tumors refractory to EGFR-TKI treatment and identify the mechanisms underlying this resistance. Thus, the therapy could be effectively tailored to each patient. Based on previous reports, the function of CEA has not been elucidated. However, as a cell surface adhesion protein, CEA may play a role in cell-cell adhesion [36]. Overexpression of CEA is thought to play a role in tumorigenesis [37]. Furthermore, CEA has a dominant effect in blocking differentiation, and CEA cooperates with Myc and $\mathrm{Bcl}-2$ during cellular transformation [38]. Furthermore, CEA can inhibit cell death induced by a loss of anchorage to the extracellular matrix (anoikis) [39]. If CEA is upregulated following activation of the EGFR pathway, its serum levels may trigger an EGFR mutation. Although these findings suggest that CEA may have anti-apoptotic effects in cancer cells, a direct relationship between high CEA levels and patient responses to EGFR-TKIs has not yet been established and requires additional research.

We found that a persistently high level of CEA after treatment with a reversible EGFR-TKI can successfully identify patients with NSCLC cells that are resistant (perhaps because of the occurrence in the EGFR kinase domain of a T790 M secondary mutation that prevents EGFR-TKI binding and subsequent growth arrest). Furthermore, when the CEA level was 16.2 times greater than normal, the elevation was associated with distant metastasis (Table 2). According to Sequist et al. [39], molecular analyses of repeated lung biopsies from these patients are needed to identify different mechanisms of acquired resistance. A potential clinical application of our observations could be the development of a test for patient responsiveness to EGFR-TKI treatment using non-invasive serum tumor markers. The information provided by this test may facilitate the selection of patients as candidates for therapy with reversible or irreversible EGFR-TKIs and the development of therapeutic strategies for overcoming resistance in patients with refractory NSCLC. Tumors with high CEA expression may possess an increased capacity to develop distant metastases (perhaps due to vascular-tumoral cell-cell adhesion processes). CEA serum levels may identify patients with a high risk of metastasis development prior to CT scans. Other cell adhesion molecular markers associated with lymph node metastasis, such as the chemokine receptors CCR7, CXCR3 and CCL21, could be related to distant metastasis development. Thus, studies of their association with distant metastasis development are justified.

In our study, the OS-associated factors were age, clinical stage, and serum CEA levels. In many neoplasms, a high serum CEA level predicts residual disease or tumor relapse in patients without normal-range serum levels 
after surgery [40]. In fact, Iwasaki et al. proposed a formula to evaluate mortality risk based on CEA serum levels, histological type, and the presence of positive mediastinal lymph nodes [41] High CEA serum levels may reflect micrometastatic disease, although we detected no differences in the CEA serum levels between patients of different clinical stages. This observation suggests that the prognostic role of high CEA serum levels may be completely accounted for by tumor change. CEA represents an important tumor marker associated with several physiopathological CEA expression is induced by hypoxia inducible factor $\alpha$ (HIF- $\alpha$ ), suggesting that CEA plays an important role as a micro-environmental factor during tumorigenesis and confers a worse prognosis.

To our knowledge, the clinical assessment of lung cancer treatment uses the RECIST criteria as the gold standard for response evaluations. However, early diagnostic CT scans for response evaluations in patients receiving EGFR-TKI therapies have severe limitations. EGFR-TKI therapy is expected to induce a response via cytostasis, rather than an objective morphologic response. The RECIST criteria are further confounded by structural abnormalities, both before and after treatment, which may not actually be tumors.

The limitations of this study should be acknowledged. There is no consensus regarding the optimal timing for performing either CT scans or serum CEA measurements during or after prolonged treatments. According to RECIST version 1.1, the best radiologic response evaluation can be obtained at least 4 weeks after the initiation of therapy. In our study, we performed CT scans every 2 weeks after the initiation of therapy. Therefore, the relatively small number of patients exhibiting a radiologic response could be explained by the timing of the CT scans. In addition, normal serum CEA levels in this study ranged from 0.0 to $3.4 \mathrm{ng} / \mathrm{ml}$, which are lower than the previously reported value of $5.0 \mathrm{ng} / \mathrm{ml}[27,42,43]$.

\section{Conclusion}

Patients with elevated serum CEA levels responded more positively to EGFR-TKIs, and lung adenocarcinoma patients with high serological CEA levels exhibited a higher rate of EGFR mutations.

In addition, we found that serum CEA levels several times higher than normal upon diagnosis was an independent prognostic factor for metastasis development particularly to the brain, liver, adrenal gland and other distant viscera - over a short time frame in patients undergoing treatment with EGFR-TKIs. Thus, patients with EGFR-TKI-resistance should undergo combined chemotherapy and radiotherapy. The feasibility of new diagnostic techniques will improve the understanding of EGFR-TKI resistance. Therefore, we believe that CEA represents a potential molecular target.

\section{Abbreviations}

CEA: Serum carcinoembryonic antigen; cftDNA: cell-free tumor DNA; $\mathrm{CT}$ : Computed tomography; EGFR: Epidermal growth factor receptor; EGFRTKI: Epidermal growth factor receptor tyrosine kinase inhibitor; NSCLC: Nonsmall cell lung cancer; RT-PCR: Real-time quantitative PCR

\section{Acknowledgements}

Not applicable.

\section{Funding}

This work was primarily supported by the Shandong Province Key Research and Development Program of China (Project No. 2016GSF201157) and National Natural Science Foundation of China (NSFC, Project NO.81602031).

\section{Availability of data and materials}

The datasets generated and analysed during the current study are not publicly available due this study is undergoing further research but are available from the corresponding author on reasonable request.

\section{Authors' contributions}

PPS and YG designed and performed experiments and wrote the manuscript; HJand BJZ provided patient material; $\mathrm{HL}$ helped to collect samples; PPS approved for the final vesion and submittion. All authors have read and approved the manuscript.

\section{Competing interest}

The authors declare that they have no competing interest.

\section{Ethics approval and consent to participate}

This study was approved by the medical ethics committee Shandong Tumor Hospital and Institute, the China (SDTHEC20130501).

All patients will be provided with written information in the form of a Patient Information Folder, including the study aims, randomization procedure, possible AEs, and their rights and responsibilities. Written informed consent must be obtained for all patients included in the study before they are randomized in the study.

Consent for publication

Not applicable.

\section{Publisher's Note}

Springer Nature remains neutral with regard to jurisdictional claims in published maps and institutional affiliations.

\section{Author details}

'Department of Thoracic Surgery, Shandong Provincial Hospital affiliated to Shandong University, Jinan, Shandong Province 250117, China. ${ }^{2}$ Department of Thoracic Surgery, Shandong Tumor Hospital and Institute, Jinan, Shandong Province 250117, China. ${ }^{3}$ Department of Medical Oncology, Shandong Tumor Hospital and Institute, Jinan, Shandong Province 250117, China. ${ }^{4}$ Department of Thoracic Surgery, Shandong Cancer Hospital and Institute, Jiyan Rd. 440, Jinan, Shandong 250117, People's Republic of China.

Received: 14 January 2016 Accepted: 6 July 2017

Published online: 14 July 2017

References

1. Ferlay J, Shin HR, Bray F, Forman D, Mathers C, Parkin DM, et al. Estimates of worldwide burden of cancer in 2008: GLOBOCAN 2008. Int J Cancer. 2010; 127:2893-917.

2. Mok TS, Wu YL, Thongprasert S, Yang CH, Chu DT, Saijo N, et al. Gefitinib or carboplatin-paclitaxel in pulmonary adenocarcinoma. N Engl J Med. 2009; 361:947-57.

3. Rosell R, Moran T, Queralt C, Porta R, Cardenal F, Camps C, et al. Screening for epidermal growth factor receptor mutations in lung cancer. $N$ Engl $J$ Med. 2009:361:958-67.

4. Zhu CQ, da Cunha SG, Ding K, Sakurda A, Cutz JC, Liu N, et al. Role of KRAS and EGFR as biomarkers of response to erlotinib in National Cancer Institute of Canada clinical trials group study BR.21. J Clin Oncol. 2008;26:4268-75.

5. Mitsudomi T, Morita S, Yatabe Y, Negoro S, Okamoto I, Tsurutani J, et al. Gefitinib versus cisplatin plus docetaxel in patients with non-small-cell lung 
cancer harbouring mutations of the epidermal growth factor receptor (WJTOG3405): an open label, randomised phase 3 trial. Lancet Oncol. 2010; 11:121-8.

6. Maemondo M, Inoue A, Kobayashi K, Sugawara S, Oizumi S, Isobe H, et al. Gefitinib or chemotherapy for non-small-cell lung cancer with mutated EGFR. N Engl J Med. 2010;362:2380-8.

7. Cappuzzo F, Ciuleanu T, Stelmakh L, Cicenas S, Szczésna A, Juhász E, et al. Erlotinib as maintenance treatment in advanced non-small-cell lung cancer: a multicentre, randomised, placebo-controlled phase 3 study. Lancet Oncol. 2010;11:521-9.

8. Shepherd FA, Rodrigues Pereira J, Ciuleanu T, Tan EH, Hirsch V, Thongprasert S, et al. Erlotinib in previously treated non-small-cell lung cancer. N Engl J Med. 2005;353:123-32.

9. Giaccone G, Gallegos Ruiz M, Le Chevalier T, Thatcher N, Smit E, Rodriguez JA, et al. Erlotinib for frontline treatment of advanced non-small cell lung cancer: a phase II study. Clin Cancer Res. 2006;12:6049-55.

10. Jackman DM, Yeap BY, Lindeman NI, Fidias P, Rabin MS, Temel J, et al Phase II clinical trial of chemotherapy-naive patients $>$ or $=70$ years of age treated with erlotinib for advanced non-small-cell lung cancer. J Clin Oncol. 2007;25:760-6.

11. Jemal A, Siegel R, Xu J, Ward E. Cancer statistics, 2010. CA Cancer J Clin. 2010;60:277-300

12. Mitsudomi T, Yatabe Y. Mutations of the epidermal growth factor receptor gene and related genes as determinants of epidermal growth factor receptor tyrosine kinase inhibitors sensitivity in lung cancer. Cancer Sci. 2007;98:1817-24.

13. Zhou C, Wu YL, Chen G, Feng J, Liu XQ, Wang C, et al. Erlotinib versus chemotherapy as first-line treatment for patients with advanced EGFR mutationpositive non-small-cell lung cancer (OPTIMAL,CTONG-0802): a multicentre, openlabel, randomised, phase 3 study. Lancet Oncol. 2011;12:735-42.

14. Kim ES, Hirsh V, Mok T, Socinski MA, Gervais R, Wu YL, et al. Gefitinib versus docetaxel in previously treated non-small-cell lung cancer (INTEREST): a randomised phase III trial. Lancet. 2008;372:1809-18.

15. Kosaka T, Yatabe Y, Endoh H, Kuwano H, Takahashi T, Mitsudomi T. Mutations of the epidermal growth factor receptor gene in lung cancer: biological and clinical implications. Cancer Res. 2004;64:8919-23.

16. Mu XL, Li LY, He QY. The diversity of epidermal growth factor receptor tyrosine kinase domain mutations and clinical features. Tumor. 2006:26:956-9.

17. Bettegowda C, Sausen M, Leary RJ, et al. Detection of circulating tumor DNA in early- and late-stage human malignancies. Sci Transl Med. 2014;6:224ra24.

18. Mandel P, Metais P. Les acides nucléiques du plasma sanguin chez I'homme. C R Seances Soc Biol Fil. 1948;142:241-3.

19. Diaz LA Jr, Bardelli A. Liquid biopsies: genotyping circulating tumor DNA. J Clin Oncol. 2014;32:579-86

20. Punnoose EA, Atwal S, Liu W, et al. Evaluation of circulating tumor cells and circulating tumor DNA in non- small cell lung cancer: association with clinical endpoints in a phase II clinical trial of pertuzumab and erlotinib. Clin Cancer Res. 2012;18:2391-401.

21. Yung TK, Chan KC, Mok TS, et al. Single-molecule detection of epidermal growth factor receptor mutations in plasma by micro uidics digital PCR in non-small cell lung cancer patients. Clin Cancer Res. 2009;15:2076-84.

22. Forshew T, Murtaza M, Parkinson C, et al. Noninvasive identi cation and monitoring of cancer mutations by targeted deep sequencing of plasma DNA. Sci Transl Med. 2012;4:136ra68.

23. Lee YJ, Yoon KA, Han JY, et al. Circulating cell- free DNA in plasma of never smokers with advanced lung adenocarcinoma receiving ge tinib or standard chemotherapy as rst-line therapy. Clin Cancer Res. 2011;17:5179-87.

24. Misale S, Yaeger R, Hobor $S$, et al. Emergence of KRAS mutations and acquired resistance to anti-EGFR therapy in colorectal cancer. Nature. 2012;486:532-6.

25. Liu P, Liang $H$, Xue L, et al. Potential clinical signi cance of plasma-based KRAS mutation analysis using the COLD-PCR/TaqMan $\left({ }^{(}\right)$-MGB probe genotyping method. Exp Ther Med. 2012;4:109-12.

26. Kokkonen N, Ulibarri IF, Kauppila A, Luosujärvi $H$, Rivinoja A, Pospiech $H$, et al. Hypoxia upregulates carcinoembryonic antigen expression in cancer cells. Int J Cancer. 2007;121:2443-50.

27. Fujishima T, Honda Y, Shijubo N, Takahashi H, Abe S. Increased carcinoembryonic antigen concentrations in sera and bronchoalveolar lavage fluids of patients with pulmonary alveolar proteinosis. Respiration. 1995;62:317-21.

28. Rule AH, Straus E, Vandevoorde J, Janowitz HD. Tumor-associated (CEAreacting) antigen in patients with inflammatory bowel disease. N Engl J Med. 1972;287:24-6.
29. Okada M, Nishio W, Sakamoto T, Uchino K, Yuki T, Nakagawa A, et al. Effect of histologic type and smoking status on interpretation of serum carcinoembryonic antigen value in non-small cell lung carcinoma. Ann Thorac Surg. 2004;78:1004-9.

30. Matsuoka K, Sumitomo S, Nakashima N, Nakajima D, Misaki N. Prognostic value of carcinoembryonic antigen and CYFRA21-1 in patients with pathological stage I non-small cell lung cancer. Eur J Cardiothorac Surg. 2007;32:435-9.

31. Okada M, Nishio W, Sakamoto T, Uchino K, Yuki T, Nakagawa A, et al. Prognostic significance of perioperative serum carcinoembryonic antigen in non-small cell lung cancer: analysis of 1,000 consecutive resections for clinical stage I disease. Ann Thorac Surg. 2004;78:216-21.

32. Okamoto T, Nakamura T, Ikeda J, Maruyama R, Shoji F, Miyake T, et al. Serum carcinoembryonic antigen as a predictive marker for sensitivity to gefitinib in advanced non-small cell lung cancer. Eur J Cancer. 2005:41:1286-90.

33. Han C, Zou H, Ma J, Zhou Y, Zhau J. Comparison of EGFR and KRAS status between primary non-small cell lung cancer and corresponding metastases: a systematic review and meta-analysis. Zhongguo Fei Ai za Zhi. 2010;13:882-91.

34. Shoji F, Yoshino I, Yano T, Kometani T, Ohba T, Kouso H, et al. Serum carcinoembryonic antigen level is associated with epidermal growth factor receptor mutations in recurrent lung adenocarcinomas. Cancer. 2007;110:2793-8.

35. Benchimol S, Fuks A, Jothy S, Beauchemin N, Shirota K, Stanners CP. Carcinoembryonic antigen, a human tumor marker, functions as an intercellular adhesion molecule. Cell. 1989;57:327-34.

36. Hammarström S. The carcinoembryonic antigen (CEA) family:structures, suggested functions and expression in normal and malignant tissues. Semin Cancer Biol. 1999;9:67-81.

37. Screaton RA, Penn LZ, Stanners CP. Carcinoembryonic antigen, a human tumor marker, cooperates with Myc and BCl-2 in cellular transformation. J Cell Biol. 1997;137:939-52.

38. Ordoñez C, Screaton RA, llantzis C, Stanners CP. Human carcinoembryonic antigen functions as a general inhibitor of anoikis. Cancer Res. 2000;60: 3419-24.

39. Sequist LV, Waltman BA, Dias-Santagata D, Digumarthy $S$, Turke AB, Fidias $P$, et al. Genotypic and histological evolution of lung cancers acquiring resistance to EGFR inhibitors. Sci Transl Med. 2011;3:75ra26.

40. Macdonald JS. Carcinoembryonic antigen screening: pros and cons. Semin Oncol. 1999;26:556-60.

41. Iwasaki A, Shirakusa T, Yoshinaga Y, Enatsu S, Yamamoto M. Evaluation of the treatment of non-small cell lung cancer with brain metastasis and the role of risk score as a survival predictor. Eur J Cardiothorac Surg. 2004;26: 488-93.

42. Nittka S, Böhm C, Zentgraf H, Neumaier M. The CEACAM1-mediated apoptosis pathway is activated by CEA and triggers dual cleavage of CEACAM1. Oncogene. 2008:27:3721-8.

43. Ilantzis C, DeMarte L, Screaton RA, Stanners CP. Deregulated expression of the human tumor marker CEA and CEA family member CEACAM6 disrupts tissue architecture and blocks colonocyte differentiation. Neoplasia. 2002:4:151-63.

\section{Submit your next manuscript to BioMed Central and we will help you at every step:}

- We accept pre-submission inquiries

- Our selector tool helps you to find the most relevant journal

- We provide round the clock customer support

- Convenient online submission

- Thorough peer review

- Inclusion in PubMed and all major indexing services

- Maximum visibility for your research

Submit your manuscript at www.biomedcentral.com/submit 